\title{
Response to "Renal Dysfunction in Heart Failure Is Due to Congestion but Not Low Output"
}

\author{
Guglin M et al. Clin Cardiol.2011;34:113-116.
}

\section{To the Editor:}

In the author's reply, Dr. Guglin states correctly that clinical evaluation of patients with heart failure is not difficult in most cases. However, in patients with heart failure and other comorbidities, many signs and symptoms may be absent or masked, and modern technology is used to collect various hemodynamic data.

Patients with significant intra-abdominal pressure (IAP) may present with elevated central venous pressure, elevated pulmonary artery occlusion pressure, decreased preload and right heart volumes, and decreased cardiac index. This, together with oliguria or anuria due to direct mechanical pressure and increased renal venous pressure, may be incorrectly interpreted as fluid overload and left ventricular failure, resulting in increased use of diuretics, decreased renal arterial blood flow, multiple organ dysfunction, and further deregulation of normovolemic patients. ${ }^{1,2}$

Dr. Guglin correctly raised some issues regarding the use of the Foley catheter. Although it may be uncomfortable and increase the risk for urinary tract infection, monitoring IAP via bladder pressure is a simple method that has 
been recommended after international consensus and can be effectively used not only in hospitals, but also in the prehospital setting. ${ }^{3}$ Therefore, as IAP monitoring may assist clinicians in accurately interpret the hemodynamic status, IAP measurement may be of great value in patients with comorbidities and worsening renal failure.

Athanasios Chalkias, $\mathrm{PhD}$

Theodoros Xanthos, $\mathrm{PhD}$

Department of Anatomy

University of Athens Medical School

Athens, Greece

\section{References}

1. Doty JM, Saggi BH, Blocher CR, et al. Effects of increased renal parenchymal pressure on renal function. J Trauma. 2000;48: 874-877.

2. Bloomfield GL, Blocher CR, Fakhry IF, et al. Elevated intraabdominal pressure increases plasma renin activity and aldosterone levels. J Trauma. 1997;42:997-1004.

3. Sugrue M. Abdominal compartment syndrome. Curr Opin Crit Care. 2005;11:333-338.

Published online in Wiley Online Library (wileyonlinelibrary.com) DOI:10.1002/clc.21957 @ 2012 Wiley Periodicals, Inc.

\section{INDEX TO ADVERTISERS}

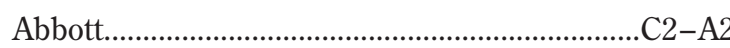

Abbott $.272-275$

Janssen. .insert

This index is provided as a service. Every effort to achieve accuracy is made. Publisher is not responsible for errors or omissions. 